\title{
STOCHASTIC PRODUCTION FRONTIER FOR THE LITHUANIAN FAMILY FARMS
}

\author{
Tomas BALEŽENTIS \\ Lithuanian Institute of Agrarian Economics, V. Kudirkos g. 18/2, \\ LT-03105 Vilnius, Lithuania \\ E-mail:tomas@laei.lt
}

Received 14 December 2012; accepted 18 January 2013

\begin{abstract}
The research follows neo-classical methodology to analyse the trends of the agricultural efficiency. The paper fits the stochastic production frontier to the micro data describing the performance of the Lithuanian family farms during 2004-2009 in order to define the current trends of efficiency and productivity in the sector. Indeed, this is the first application of stochastic frontiers to gauge the performance of Lithuanian family farms. The technical efficiency of the Lithuanian family farms fluctuated around $80 \%$. The analysis confirmed that the livestock farms were peculiar with higher mean technical efficiency if compared to that of mixed or crop farms. The estimated partial output elasticities imply that the intermediate consumption was the most productive factor, whereas assets were four to six times less productive depending on the farming type. The land factor was peculiar with the lowest partial output elasticities. The research contributes to the wider discussion on the patterns of efficiency and productivity in a transition European Union Member States following the accession.
\end{abstract}

Keywords: technical efficiency, total factor productivity, input elasticity, stochastic frontier analysis, family farms, Lithuania.

JEL Classification: D22, C01, Q12.

\section{Introduction}

Productivity and efficiency are the two important factors of competitiveness for any economic activity. Indeed, they tend to affect profitability which, in turn, determines the viability of producers. As for agricultural sector, efficiency is particularly related to labour intensity, management skills, farm structure, and technologies (Henningsen 2009).

Performance management aims at identifying and spreading the best practices within an organization, sector, or the whole economy. The relative performance evaluation benchmarking - is the systematic comparison of one production entity (decision making unit) against other entities (Bogetoft, Otto 2011). Indeed, benchmarking is an important issue for both private and public decision makers to ensure the sustainable change. Due to Jack and Boone (2009) benchmarking can create motivation for change; provide a vision for what an organization can look like after change; provide data, evidence, and 
success stories for inspiring change; identify best practices for how to manage change; and create a baseline or yardstick by which to evaluate the impact of earlier changes.

Reasonable strategic decision making requires an integrated assessment of the regulated sector. The agricultural sector is related to voluminous public support as well as regulations. The application of benchmarking, thus, becomes especially important when fostering sustainable agricultural development. Furthermore, productive efficiency gains might result into lower costs as well as greater profit margins for the producer and better prices for the participants in the agricultural supply chain (Samarajeewa et al. 2012). Nauges et al. (2011) presented the following factors stressing the need for research into agricultural efficiency. First, agricultural producers typically own land and live on their farms, therefore the standard assumption that only efficient producers are to maintain their market activity usually does not hold in agriculture; moreover, suchlike adjustments would result in various social problems. Second, it is policy interventions - education, training, and extension programmes - that should increase the efficiency. Third, policy issues relating to farm structure are of high importance across many regions. The discussed issues require an appropriate methodology for estimation of productive efficiency in the agricultural sector.

It is due to Alvarez and Arias (2004), Gorton and Davidova (2004) that frontier techniques are the most widely applied methods for efficiency measurement in agriculture. Indeed, the frontier methods can be grouped into parametric and non-parametric ones (Murillo-Zamorano 2004). Parametric methods are employed to estimate the parameters of a pre-defined production function, whereas non-parametric methods define the production frontier empirically. A further distinction can be made between stochastic and deterministic methods. Specifically, the stochastic methods treat the distance between a production function and a certain observation as a combination of both random error and inefficiency. The deterministic methods attribute the whole distance to either inefficiency or random error. There are many arguments supporting either of the discussed techniques, therefore one needs to employ different methods to perform a robust analysis. Rasmussen (2011) employed stochastic frontier analysis for the Danish farms. Chou et al. (2012) employed stochastic frontier analysis to measure performance of the IT capital goods sectors across OECD countries. Zhan (2012) analysed the properties of different stochastic frontier specifications. Bojnec and Latruffe (2011) as well as Davidova and Latruffe (2007) applied data envelopment analysis to assess the performance of Slovenian and Czech farms, respectively. Latruffe et al. (2004) applied both stochastic frontier analysis and data envelopment analysis to analyse the technical efficiency of the Polish farms. Bravo-Ureta et al. (2007) provided a meta-analysis of farm efficiency research in multiple countries.

The Lithuanian agricultural sector was analyzed by the means of a non-parametric deterministic method viz. data envelopment analysis (Baležentis, Kriščiukaitienè 2012). However, the stochastic parametric methods have not been employed in the latter area so far. This paper fits the translog production frontier for the Lithuanian family farms. The research covers the period of 2004-2009 and relies on the reports of the Farm Accountancy Data Network. 


\section{Preliminaries}

\subsection{Stochastic frontier analysis}

The econometric techniques of production analysis can be grouped into deterministic and stochastic ones. The deterministic techniques, e. g. ordinary least squares (OLS), corrected ordinary least squares (COLS), assume that the whole error term is caused by either inefficiency or statistical noise. The OLS estimation of the production function assumes that the distance between an observation and the production frontier is purely determined by the random error, whereas COLS explain the same distance by inefficiency. The stochastic techniques, e. g. stochastic frontier analysis (SFA), allow both statistical noise and the inefficiency to influence the error term. Accordingly, the stochastic methods unify the advantages of both OLS and COLS. The remaining drawback is that a researcher still needs to define the functional form of the production function.

The two functional forms are usually employed for SFA, viz. Cobb-Douglas (Cobb, Douglas 1928) and Translog (Christensen et al. 1971, 1973). The logged Cobb-Douglas production function has the following form:

$$
\ln y_{k}=\ln \beta_{0}+\sum_{i=1}^{m} \beta_{i} \ln x_{i}^{k}+v_{k}-u_{k},
$$

where: $k=1,2, \ldots, K$ denotes the $k$-th farm, $y$ and $x$ are output and input quantities, respectively, and $i=1,2, \ldots, m$ stands for the $i$-th input; $v_{k} \sim \operatorname{iid} N\left(0, \sigma_{v}^{2}\right)$ is the statistical noise term accounting for measurement errors etc., and $u_{k} \sim i i d N^{+}\left(0, \sigma_{u}^{2}\right)$ is the inefficiency term. The technical efficiency of the $k$-th farm is given by $T E_{k}=\exp \left(-u_{k}\right)$, with $T E_{k}=1$ for efficient farms and $T E_{k} \in(0,1)$ otherwise. Indeed, only the whole error term $e_{k}=v_{k}-u_{k}$ can be observed. Since the inefficiency term, $v_{k}$, cannot be observed directly, it is predicted by its conditional expectation with respect to the value of $e_{k}$ : $E\left(u_{k} \mid e_{k}\right)$ (Coelli et al. 2005; Latruffe et al. 2004).

The translog (Transcendental Logarithmic) production function is a generalization of the Cobb-Douglas function:

$$
\ln y_{k}=\beta_{0}+\sum_{i=1}^{m} \beta_{i} \ln x_{i}^{k}+\frac{1}{2} \sum_{i=1}^{m} \sum_{l=1}^{m} \beta_{i l} \ln x_{i}^{k} \ln x_{l}^{k}+v^{k}-u^{k},
$$

with symmetry imposed by setting $\beta_{i j}=\beta_{j i}$. In case one analyzes the longitudinal data. The time index $t$ is introduced. Furthermore, the non-neutral technical change can be tackled by considering the time factor as an input in Eq. (2):

$$
\begin{aligned}
& \ln y_{k}^{t}=\beta_{0}+\sum_{i=1}^{m} \beta_{i} \ln x_{i}^{k t}+\frac{1}{2} \sum_{i=1}^{m} \sum_{l=1}^{m} \beta_{i l} \ln x_{i}^{k t} \ln x_{l}^{k t}+ \\
& \beta_{t} \ln t+\sum_{i=1}^{m} \beta_{i t} \ln x_{i}^{k t} t+\frac{1}{2} \beta_{t t} t^{2}+v^{k}-u^{k},
\end{aligned}
$$

where $t$ denotes a respective time period.

\subsection{Total factor productivity change}

The economic performance can be evaluated in terms of efficiency and productivity. Whereas efficiency defines the distance between a certain production plan and respective production frontier, productivity is related to the very location of the frontier. Ac- 
cordingly, productivity measure describing the multi-input and multi-output technology is referred to as the total factor productivity. The Malmquist productivity index can be employed to estimate total factor productivity (TFP) changes of a single firm over the two periods (or vice versa), across two production modes, strategies, locations etc. In this study we shall focus on output-oriented Malmquist productivity index and apply it to measure period-wise changes in TFP. The output-oriented Malmquist productivity index due to Caves et al. (1982) is defined as:

$$
M_{o}=\left(M_{o}^{0} \cdot M_{o}^{1}\right)^{1 / 2}=\left(\frac{D_{o}^{0}\left(x^{1}, y^{1}\right)}{D_{o}^{0}\left(x^{0}, y^{0}\right)} \frac{D_{o}^{1}\left(x^{1}, y^{1}\right)}{D_{o}^{1}\left(x^{0}, y^{0}\right)}\right)^{1 / 2},
$$

where $D^{\tau}{ }_{O}\left(x^{\tau}, y^{\tau}\right)$ is the Shepard efficiency measure (distance function) and $\tau=\{0,1\}$ with indices 0 and 1 representing respective time periods. The two terms in brackets follows the structure of Fisher's index. Consequently a number of studies attempted to decompose the latter index into different terms each explaining certain factors of productivity shifts. Specifically, Färe et al. (1992) decomposed productivity change into efficiency change (EC or catching up) and technical change (TC or shifts in the frontier):

$$
M_{o}=E C \cdot T C,
$$

where

$$
E C=D_{o}^{1}\left(x^{1}, y^{1}\right) / D_{o}^{0}\left(x^{0}, y^{0}\right)
$$

and

$$
T C=\left(\frac{D_{o}^{0}\left(x^{1}, y^{1}\right)}{D_{o}^{1}\left(x^{1}, y^{1}\right)} \frac{D_{o}^{0}\left(x^{0}, y^{0}\right)}{D_{o}^{1}\left(x^{0}, y^{0}\right)}\right)^{1 / 2} .
$$

EC measures the relative technical efficiency change. The index becomes greater than unity in case the firm approaches frontier of the current technology. TC indicates whether the technology has progressed and thus moved further away from the observed point. In case of technological progress, the TC becomes greater than unity; and that virtually means that more can be produced using fewer resources. Given the Malmquist productivity index measures TFP growth, improvement in productivity will be indicated by values greater than unity, whereas regress - by that below unity.

The distance functions involved in Eqs (6)-(7) can be approximated by employing SFA (Fuentes et al. 2001; Coelli et al. 2005). Let $t$ and $s$ denote the two adjacent time periods. The technical efficiency can be obtained via $T E_{k}^{t}=E\left(\exp (-u) \mid e_{k}^{t}\right)$. The latter measure, indeed, is an estimation of the distance function such that $D_{o}^{\tau}\left(x^{\tau}, y^{\tau}\right)=T E_{k}^{\tau}, \tau=\{t, s\}$. Specifically, the EC component between the two time periods, $t$ and $s$, is then computed as follows:

$$
E C=T E_{k}^{s} / T E_{k}^{t}
$$

Meanwhile, the TC component can be obtained by the virtue of the following equation:

$$
T C=\exp \left(\frac{1}{2}\left(\frac{\partial y_{k}^{t}}{\partial t}+\frac{\partial y_{k}^{s}}{\partial s}\right)\right)
$$


In case the underlying technology is VRS one can also identify the scale efficiency component. The total factor productivity change is obtained by multiplying the EC and TC obtained from Eqs (8) and (9):

$$
T F P=E C \cdot T C .
$$

The values of the three measures discussed above become greater (lower) than unity in case of technological progress (regress).

\subsection{Returns to scale and SFA}

The econometric approach allows one to estimate the partial output elasticities with respect to different inputs. Specifically, output elasticity with respect to the time trend captures the technological change. The partial elasticity indicates the percentage change of output caused by one per cent increase in a certain input. In case of the translog production function, the partial output elasticity with respect to the $i$-th input, $\varepsilon_{i}^{k}$, is obtained by differentiating the production function with respect to a certain input:

$$
\varepsilon_{i}^{k}=\frac{\partial \ln y_{k}^{t}}{\partial \ln x_{i}^{k t}}=\beta_{i}+\sum_{l=1}^{m} \beta_{i l} \ln x_{l}^{k t}+\beta_{i t} t .
$$

Meanwhile, the total output elasticity, $\varepsilon_{k}$, is the sum of the partial elasticities:

$$
\varepsilon_{k}=\sum_{i=1}^{m} \varepsilon_{i}^{k}
$$

with value greater than unity indicating increasing returns to scale (IRS), that equal to unity indicating constant returns to scale (CRS), and that lower than unity indicating decreasing returns to scale (DRS). Note that these elasticities are firm- and time-variant ones. Therefore, they can also be evaluated at the sample means or one can consider their means.

The linear hypothesis of constant returns to scale technology can be tested by constructing a $t$ statistic (Bogetoft, Otto 2011). Let $\theta$ be a column vector of the Maximum Likelihood estimates for a translog function and $\lambda$ be a row vector of the same dimension with values of unity for elements corresponding to beta coefficients in $\theta$ and zeros otherwise. Furthermore, let $V$ be the variance matrix of parameters, viz. betas. The variance of the sum of parameters is then calculated as $\operatorname{Var}(\lambda \theta)=\lambda \operatorname{Var}(\theta) \lambda^{T}=\lambda V \lambda^{T}$. The test statistic for the null hypothesis that $\lambda \theta$ equals unity, i. e. the underlying technology is CRS, is given by:

$$
S=\frac{\lambda \theta-1}{\sqrt{\lambda V \lambda^{T}}},
$$

which follows the $t$ distribution. In case $S>t\left(\alpha / 2, K-(m+1)-(m+1)^{2}\right)$ the underlying technology is IRS, whereas $S<-t\left(\alpha / 2, K-(m+1)-(m+1)^{2}\right)$ implies DRS; otherwise CRS is assumed. 


\section{Data used}

The data for 200 farms selected from the FADN sample cover the period of 2004-2009. Thus a balanced panel of 1200 observations is employed for analysis. The technical efficiency was assessed in terms of the input and output indicators commonly employed for agricultural productivity analyses. More specifically, the utilized agricultural area (UAA) in hectares was chosen as land input variable, annual work units (AWU) - as labour input variable, intermediate consumption in Litas, and total assets in Litas as a capital factor. The UAA variable measures both own and rented area employed for the agricultural production. AWU corresponds to the work performed by one person who is occupied on an agricultural holding on a full-time basis (eight hours per day). Intermediate consumption catches the goods that are transformed during the agricultural production process, viz. seeds, feed, fertilizers, fuel etc. Total asset variable is the value of the fixed assets utilized in farming. The last two variables were deflated by respective real price indices provided by Eurostat. On the other hand, the three output indicators represent crop, livestock, and other outputs in Litas (Lt), respectively. The aforementioned three output indicators were deflated by respective price indices and aggregated into a single one.

The analysed sample covers relatively large farms (mean UAA - 244 ha). As for labour force, the average was 3.6 AWU. One can note that crop farms were specific with the highest variation of the variables under analysis save AWU. Table 1 summarizes the main statistics of the deflated variables. The data in Table 1 do indicate that there exists a substantial variation to employ the econometric methods.

Table 1. Descriptive statistics of the analysed variables

\begin{tabular}{lccccccc}
\hline & 2004 & 2005 & 2006 & 2007 & 2008 & 2009 & Average \\
\hline & \multicolumn{7}{c}{ Average } \\
\hline Total output (Lt) & 333811 & 367627 & 359039 & 682064 & 787855 & 580777 & 518529 \\
\hline Labour (AWU) & 3.1 & 3.3 & 3.5 & 3.7 & 4.0 & 3.9 & 3.6 \\
\hline UAA (ha) & 202 & 226 & 248 & 255 & 265 & 270 & 244 \\
\hline $\begin{array}{l}\text { Intermediate } \\
\text { consumption (Lt) }\end{array}$ & 183120 & 231629 & 266368 & 326115 & 434769 & 423125 & 310854 \\
\hline Assets (Lt) & 521717 & 644508 & 781031 & 1098371 & 1294329 & 1304569 & 940754 \\
\hline & \multicolumn{7}{c}{ Standard deviation } \\
\hline Total output (Lt) & 327425 & 350854 & 356292 & 700460 & 856434 & 633136 & 599945 \\
\hline Labour (AWU) & 2.5 & 2.1 & 2.2 & 2.5 & 2.9 & 2.7 & 2.5 \\
\hline UAA (ha) & 191 & 212 & 219 & 221 & 229 & 240 & 220 \\
\hline $\begin{array}{l}\text { Intermediate } \\
\text { consumption (Lt) }\end{array}$ & 180104 & 222842 & 247956 & 306627 & 450010 & 436707 & 336897 \\
\hline Assets (Lt) & 589959 & 695486 & 780794 & 1087151 & 1334451 & 1312195 & 1054508 \\
\hline
\end{tabular}




\section{Technical efficiency and productivity}

\subsection{Production function and TE scores}

The SFA was employed to estimate the efficiency scores for the family farms. The panel data were analysed in a cross-section way (cf. Eq. (3)). A series of LR tests was carried out before arriving at the non-neutral model. The labour variable as well as its interactions with remaining ones turned out to be insignificant and thus were removed from the further analysis. This finding might have stemmed from methodological or economic peculiarities. As for the methodological issues, the FADN practice might need some improvements on estimation of the labour amount involved in the agricultural production. Specifically, part-time work can be the hardest observable variable. On the other hand, the Lithuanian family farms might not be eager to report the accurate figures about the paid labour force due to legal regulations.

The final specification of the stochastic translog production function is, therefore, given in Table 2. The time trend is not significant, but indicates a technical progress of some $4.7 \%$ per year, whereas the squared trend is negative and a significant one thus inducing that technical progress increases at a decreasing rate. The positive coefficients near interactions between the time trend and intermediate consumption and utilized land area imply that the technical progress was factor-saving in terms of the latter two types of inputs. On the other hand, the negative coefficient associated with trend and asset interaction indicates increasing asset intensity in the production processes.

As one can note, inefficiency accounted for some $67 \%$ of the total variation of the error term. The mean technical efficiency (TE) score was 0.76 , which implies that output should be increased by some $30 \%$ on average.

Figure 1 depicts the mean values of TE scores across different farming types. Indeed, the farm sample was classified into the three farming type sub-samples in terms of the output structure: Farms with livestock (crop) output accounting for more than 2/3 of the total output were considered as the specialised livestock (crop) farms, whereas the remaining ones were considered as the mixed farms. As one can note, the mean TE had been declining since 2004 and reached its trough in 2006. This particular fall was influenced by unfavourable climatic conditions. After recovering in 2007, the TE further declined during 2008-2009. Noteworthy, the crop farms were specific with higher efficiency fluctuations if compared to livestock or mixed ones. Furthermore, the livestock farms were specific with the highest mean TE scores throughout the research period save year 2004.

The previous Figure 1 exhibits the means values, whereas the underlying distribution of efficiency scores remains unknown. In order to cope with the latter issue, the kernel densities are usually employed in efficiency analyses. This type of graphic representations enables one to avoid arbitrary decisions involved in construction of the other ones (e.g. the different numbers of bins in histograms are related with different visualisations of the same efficiency score distribution). Figure 2 thus exhibits the underlying distributions of the TE scores across the three farming types. The mean TE scores of each farming type are quite similar: 0.8 for livestock farms and 0.77 for both crop and mixed farms. 
Table 2. The estimated stochastic production frontier for the Lithuanian family farms (2004-2009)

\begin{tabular}{|c|c|c|c|c|c|}
\hline & Estimate & Standard error & $\mathrm{z}$ value & $\operatorname{Pr}(>|z|)$ & \\
\hline Intercept & 5.7128 & 2.1097 & 2.7078 & 0.006773 & $* *$ \\
\hline $\log (\operatorname{Int})$ & 0.7480 & 0.5585 & 1.3393 & 0.180462 & \\
\hline $\log$ (Assets) & -1.0967 & 0.3207 & -3.4195 & 0.000627 & $* * *$ \\
\hline $\log (\mathrm{UAA})$ & 1.5083 & 0.4904 & 3.0753 & 0.002103 & $* *$ \\
\hline$(\log ($ Int $) * \log ($ Assets $))$ & 0.0724 & 0.0519 & 1.3958 & 0.162764 & \\
\hline$(\log (\operatorname{Int}) * \log (\mathrm{UAA}))$ & -0.1731 & 0.0870 & -1.9906 & 0.046524 & $*$ \\
\hline$(\log ($ UAA $) * \log ($ Assets $))$ & -0.0001 & 0.0457 & -0.0033 & 0.997404 & \\
\hline$\left(0.5 * \log (\operatorname{Int})^{\wedge} 2\right)$ & -0.0078 & 0.1042 & -0.0747 & 0.940471 & \\
\hline$\left(0.5 * \log (\text { Assets })^{\wedge} 2\right)$ & 0.0339 & 0.0433 & 0.7843 & 0.432888 & \\
\hline$\left(0.5 * \log (\mathrm{UAA})^{\wedge} 2\right)$ & 0.1286 & 0.0898 & 1.4315 & 0.152288 & \\
\hline $\mathrm{t}$ & 0.0466 & 0.1146 & 0.4062 & 0.684624 & \\
\hline$\left(0.5 * \mathrm{t}^{\wedge} 2\right)$ & -0.0253 & 0.0080 & -3.1427 & 0.001674 & $* *$ \\
\hline$(\mathrm{t} * \log ($ Int $))$ & 0.0221 & 0.0179 & 1.2334 & 0.217425 & \\
\hline$(\mathrm{t} * \log ($ Assets $))$ & -0.0298 & 0.0112 & -2.6738 & 0.0075 & $* *$ \\
\hline$(\mathrm{t} * \log (\mathrm{UAA}))$ & 0.0109 & 0.0168 & 0.6451 & 0.518868 & \\
\hline sigmaSq & 0.1808 & 0.0172 & 10.5371 & $<2.2 \mathrm{e}-16$ & $* * *$ \\
\hline gamma & 0.6665 & 0.0689 & 9.6704 & $<2.2 \mathrm{e}-16$ & $* * *$ \\
\hline \multicolumn{6}{|c|}{ log likelihood value: -337.2857} \\
\hline \multicolumn{6}{|c|}{ total number of observations $=1200$} \\
\hline mean efficiency: 0.77 & & & & & \\
\hline
\end{tabular}

Notes: (i) Int, Assets, $U A A$, and $t$ stand for intermediate consumption, asset value, utilized agricultural area, and time trend, respectively; (ii) significance codes: ${ }^{* * *}-0.001 ; * *-0.01 ; *-0.05$.

However, the crop farm distribution is right-skewed and specific with a higher variance if compared to those of the remaining farming types. The lowest variance of the livestock farm TE score distribution implies that these farms are quite homogeneous in terms of technical efficiency, whereas crop and mixed farms tend to be more heterogeneous.

In order to test whether the differences of the mean TE are significant across farming types, the Least Significant Difference (LSD) test was employed. The results (see Appendix) imply that livestock farms had a significantly higher mean of TE scores at the confidence level of 5\%. Indeed, the difference between livestock and crop farms was more significant $(p=0.001)$ than that between livestock and mixed farms $(p=0.017)$. Therefore, the mixed farms do benefit from animal farming in terms of efficiency gains. 


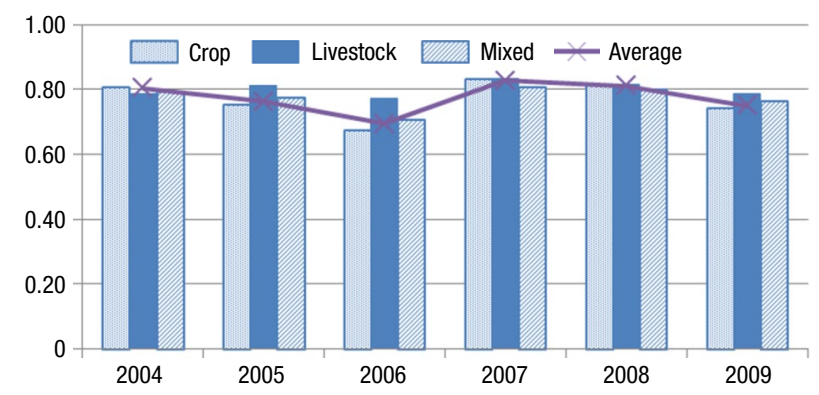

Fig. 1. Mean TE scores across different farming types, 2004-2009

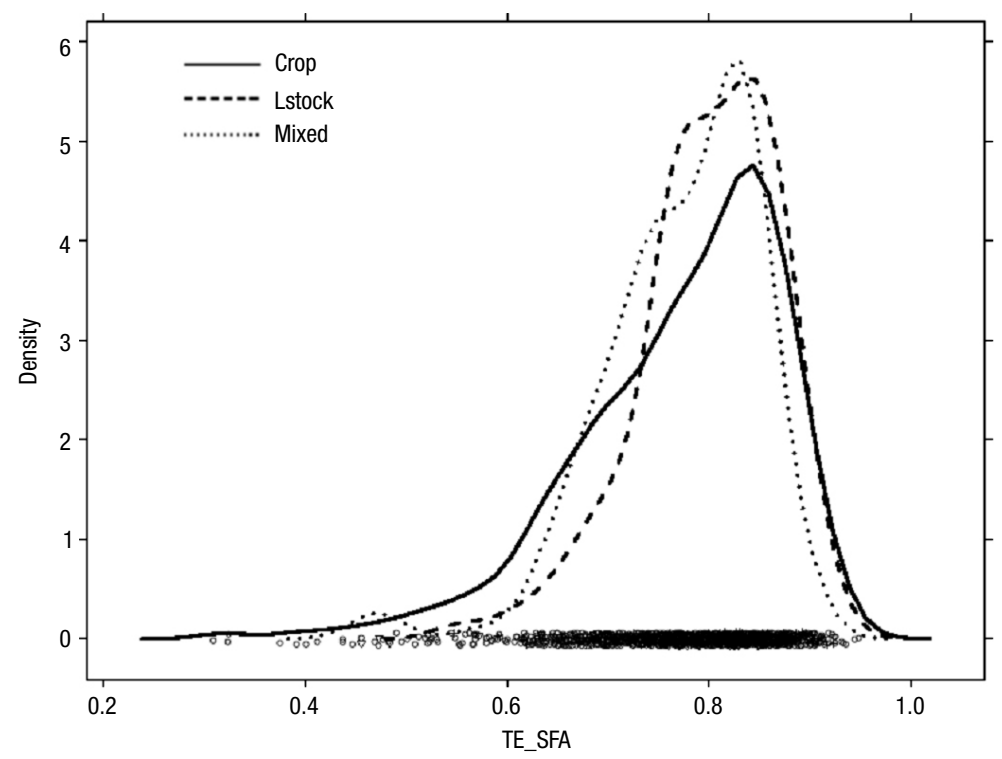

Fig. 2. Kernel densities of the TE scores across different farming types

\subsection{Elasticities}

The partial output elasticities help one to fathom the prospective ways to improve the productive efficiency with respect to the underlying productive technology. The elasticity analysis is related to factor input rationing, for scarce resources should induce higher output elasticities and shadow prices. In the sequel we will analyse the dynamics of the three inputs, viz. assets, intermediate consumption, and land as described in Eq. (11). The time elasticity is to be analysed alongside with the total factor productivity.

The output elasticities with respect to assets are given in Table 3. As one can note, assets became less productive throughout the research period: An additional per cent of assets would have resulted in $0.14-0.27$ increase in output in 2004, whereas it would have caused an increase of only $0.1-0.21$ in 2009 . This finding is alongside with the negative coefficient observed for an interaction between trend and assets. The latter developments 
might be related with excessive capital use (Petrick, Kloss 2012), which, in turn, was fuelled by investment subsidies distributed in accordance with the Common Agricultural Policy after Lithuania acceded to the European Union. Noteworthy, it was the mixed farms that were specific with the lowest output elasticity to assets. Indeed, these farms have accumulated the highest amounts of fixed assets. Therefore, the investment support policy should be reconsidered for this particular farming type.

Table 3. Output elasticity with respect to assets, 2004-2009

\begin{tabular}{cccc}
\hline \multirow{2}{*}{ Year } & \multicolumn{3}{c}{ Farming type } \\
\cline { 2 - 4 } & Crop & Livestock & Mixed \\
\hline 2004 & 0.26 & 0.27 & 0.14 \\
\hline 2005 & 0.26 & 0.23 & 0.17 \\
\hline 2006 & 0.25 & 0.22 & 0.15 \\
\hline 2007 & 0.24 & 0.21 & 0.16 \\
\hline 2008 & 0.24 & 0.23 & 0.13 \\
\hline 2009 & 0.21 & 0.19 & 0.10 \\
\hline Average & 0.25 & 0.23 & 0.14 \\
\hline
\end{tabular}

Table 4. Output elasticity with respect to intermediate consumption, 2004-2009

\begin{tabular}{cccc}
\hline \multirow{2}{*}{ Year } & \multicolumn{3}{c}{ Farming type } \\
\cline { 2 - 4 } & Crop & Livestock & Mixed \\
\hline 2004 & 0.64 & 0.77 & 0.81 \\
\hline 2005 & 0.65 & 0.79 & 0.77 \\
\hline 2006 & 0.66 & 0.81 & 0.79 \\
\hline 2007 & 0.71 & 0.86 & 0.84 \\
\hline 2008 & 0.73 & 0.86 & 0.86 \\
\hline 2009 & 0.75 & 0.89 & 0.88 \\
\hline Average & 0.69 & 0.83 & 0.83 \\
\hline
\end{tabular}

Elasticity associated with intermediate consumption (cf. Table 4) increased during the period of 2004-2009 from 0.64-0.81 up to 0.75-0.89. The increase might have been driven by improved farming practices, novel chemical products, and successful training programs. The lowest output elasticity to intermediate consumption was observed for the crop farms. Specifically, it constituted some $74-84 \%$ of the respective mean elasticity observed for either livestock or mixed farms, depending on which of them was a higher one, during 2004-2009. The crop farms are specific with inflated intermediate consumption values with fertilizer costs accounting for a significant share therein. Therefore, both introduction of new species and application of effective fertilizing schemes are still important for the crop farming. Anyway, the crop farming elasticity associated with intermediate consumption exhibited a positive trend and tended to converge with those specific for livestock and mixed farms.

The output elasticity with respect to utilized agricultural land was generally decreasing from 0.02-0.14 down to 0.01-0.1 during the period of 2004-2009 (cf. Table 5). The range of mean elasticities across farming types, though, remained virtually invariant. The mixed farms were specific with the highest elasticity, whereas the livestock - with the lowest one and even a negative value for year 2008. Indeed, livestock farming does not require land as a production factor to the same extent as other farming types do. There are still some prospects to increase land productivity in the livestock farms mainly by producing fodder.

The analysis of the partial output elasticities implies that the Lithuanian family farms face rather meagre difficulties in land acquisition. For the mean partial elasticity as- 
sociated with land, equal to 0.06 , was the lowest one if compared to those associated with intermediate consumption or assets. The marginal asset productivity represented by respective elasticity $(0.23)$ was much higher than that of land, albeit it was downtrended. Therefore, the excessive use of assets should be reduced by streamlining support measures under Rural Development Programme for 2014-2020. Finally, the highest output elasticity was that with respect to intermediate consumption. Indeed, this type of input is the one easy controllable and adjustable.

Table 5. Output elasticity with respect to utilized agricultural area, 2004-2009

\begin{tabular}{cccc}
\hline \multirow{2}{*}{ Year } & \multicolumn{3}{c}{ Farming type } \\
\cline { 2 - 4 } & Crop & Livestock & Mixed \\
\hline 2004 & 0.09 & 0.02 & 0.14 \\
\hline 2005 & 0.07 & 0.05 & 0.10 \\
\hline 2006 & 0.07 & 0.05 & 0.11 \\
\hline 2007 & 0.05 & 0.03 & 0.09 \\
\hline 2008 & 0.03 & -0.02 & 0.09 \\
\hline 2009 & 0.04 & 0.01 & 0.10 \\
\hline Average & 0.06 & 0.03 & 0.10 \\
\hline
\end{tabular}

The total output elasticity was computed in order to test whether the underlying technology is CRS or VRS. The linear hypothesis of CRS was tested in the spirit of Eq. (13). The obtained statistic $(S=0.85)$ was well below the critical value. The null hypothesis about CRS was, therefore, accepted. In the remaining part of the research we therefore did not tackle the scale efficiency.

\subsection{Total factor productivity}

The economic performance of a decision making unit should be assessed not only in terms of efficiency but also in productivity. For efficiency measures the firm-specific distance from the production frontier, whereas the total factor productivity describes the shifts of the production frontier. Therefore, a certain firm might not reduce its technological features but become less efficient due to the frontier shift, i. e. increase in the sectorial total factor productivity. On the other hand, a certain firm can maintain the same level of efficiency and become more productive in case it catches up the frontier shift and thus increases its productivity.

The total factor productivity (TFP) change was assessed across the three farming types in terms of Eqs (8)-(10). Given the fact that the CRS technology was assumed on a basis of the linear hypothesis test, the TFP change was decomposed into the two terms, namely technical change (TC) and efficiency change (EC). The estimates for each farming type are given in Figures 3-5.

The crop farms were peculiar with the most intensive fluctuations of the TFP (Fig. 3). The TFP increased during 2004-2005 and 2006-2007, whereas it decreased during 
2005-2006 and 2007-2009. The decrease of 2005-2006 was mainly driven by a negative EC effect, what means that unfavourable climatic conditions decreased the TE of the crop farms. The TC, though, did not change if compared to the preceding period and the cumulative change remained greater than unity. Therefore, the production frontier did not move inwards, but the efficiency of an average crop farm tended to decrease. A certain part of the crop farms, nevertheless, remained working as productive as in the preceding period. The EC caused decrease of the TFP to margin of $3 \%$, whereas TC - to that of $10 \%$ during the period of 2004-2009. The very TFP decreased by some $13 \%$ in the meantime.

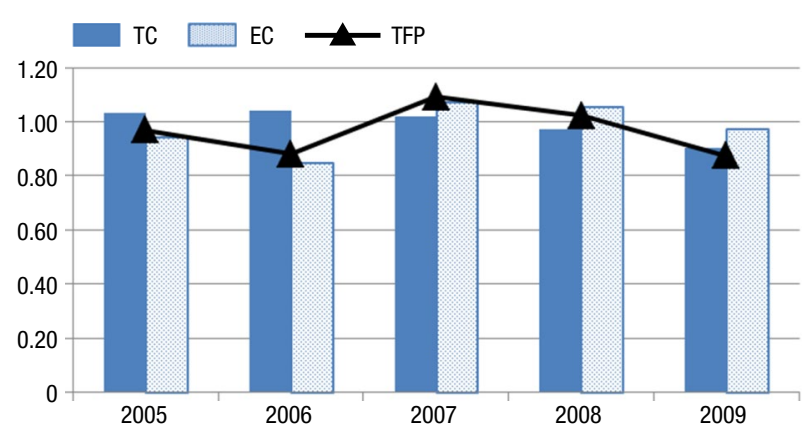

Fig. 3. The cumulative total factor productivity change in the crop farms, 2004-2009

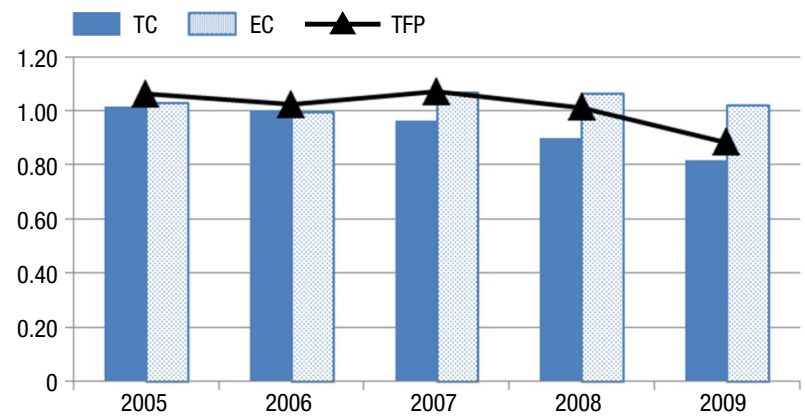

Fig. 4. The cumulative total factor productivity change in the livestock farms, 2004-2009

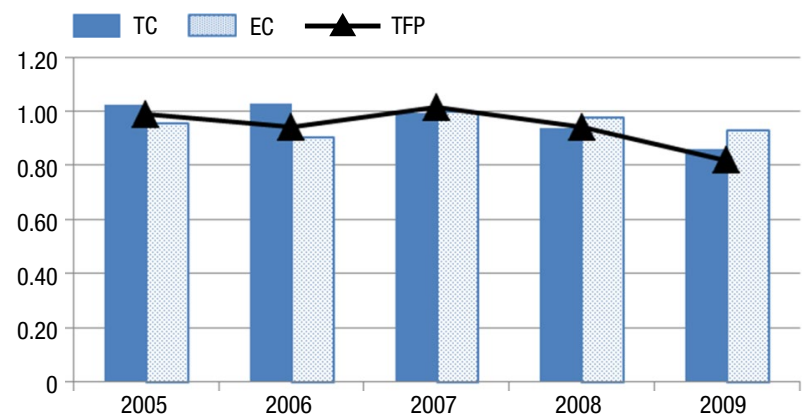

Fig. 5. The cumulative total factor productivity change in the mixed farms, 2004-2009 
The livestock farms were specific with the lowest fluctuations in the TFP throughout 2004-2009 (Fig. 4). The latter sub-sector remained virtually unaffected by the downturn of 2005-2006, albeit the subsequent periods were specific with a negative TC trend. Accordingly the TFP began to diminish after year 2007. As a result, the TC resulted in the decline of the TFP by some $18 \%$, whereas the EC component accounted for the increase of some 2\%. The resulting TFP change during 2004-2009 was a decrease of $12 \%$. The observed changes in TFP indicate that it was the TC that reduced the TFP, whereas the livestock farms became more homogeneous in terms of the TE, because the cumulative EC remained positive (i. e. that above unity). The decreasing number of livestock is obviously related to the diminishing TFP. The frontier movement inwards could be alleviated by introducing respective support measures aimed at increasing the attractiveness of the livestock farming as an economic activity.

The mixed farming was specific with a degree of the TFP variation that lies in between those of the specialised farms (Fig. 5). Anyway, the mixed farms did not manage to maintain neither the TC level specific for the crop farms nor the EC experienced by the livestock farms. The mixed farming, therefore, was specific with the highest decrease in the TFP accounting for $18 \%$. The results do indicate that the mixed farms should receive more attention when preparing the training and support programs in terms of efficient managerial and agricultural decisions.

\section{Conclusions}

The paper fitted the stochastic production frontier to the micro data describing the performance of the Lithuanian family farms during 2004-2009. The sample of 200 family farms was utilized to define the current trends of efficiency and productivity in the sector. One of the main limitations of the research was the lack of information on farm production or cost structure. Nevertheless, the technical efficiency scores, output elasticities, and the total factor productivity change were estimated.

Out of the initial four input indicators representing land, labour, intermediate consumption, and assets the one associated with labour was dropped due to the resulting insignificancies. Accordingly, this finding might imply that either labour input is the extremely variant one across the observed farms or certain methodological discrepancies do underlie the estimation of this particular variable. The technical efficiency of the Lithuanian family farms fluctuated around $80 \%$. The least significant difference test and the kernel density plots confirmed that the livestock farms were peculiar with the highest mean technical efficiency if compared to that of mixed or crop farms. The high variation specific for the distribution of the technical efficiency scores of the crop farms imply that a significant part of these farms need to improve their practices in order to approach the production frontier. Accordingly, the policy measures aimed at modernization and training schemes are likely to increase the efficiency of the crop farming. The livestock farms were specific with the highest mean technical efficiency. The latter finding follows the trends observed in other countries, as reported by Bravo-Ureta et al. (2007).

The estimated partial output elasticities imply that the intermediate consumption was the most productive factor, whereas assets were four to six times less productive depending 
on the farming type. The land factor was peculiar with the lowest partial output elasticities. The following policy implications related to the factor markets can be drawn from the carried out research. The mixed farms were specific with the lowest partial output elasticities associated with assets. Consequently, the new policy measures should not encourage further accumulation of equipment (i. e. the fixed assets) in the mixed farms but rather focus on the equipment subsidies for the specialised farms. The lowest output elasticity with respect to the intermediate consumption was observed for the crop farms. These farms, therefore, need to improve their crop-mix as well as fertilizing practice. The partial output elasticity with respect to land was the lowest one and thus indicated that the land market and land use policy need to be further developed in Lithuania.

The hypothesis of the constant returns to scale technology was not rejected. The total factor productivity change was therefore decomposed into the two terms accounting for the technological and efficiency change, respectively. The results do indicate that the technical change was generally decreasing to a higher extent than efficiency change did. Therefore, the negative trends of technical change might not be compensated even by the upward shifts in efficiency.

The research contributes to the literature by demonstrating the patterns of efficiency and productivity in a new EU Member State, viz. Lithuania, during the period immediately after accession to the EU. The findings presented in the study will thus enable to draw more general conclusions in regards to the effects of the Common Agricultural Policy.

The further studies should tackle the farm heterogeneity by employing panel models or defining separate frontiers for each farming type. In addition, the dynamic change of the efficiency scores' distribution could be imposed by the virtue of the efficiency effects model. The determinants of efficiency can also be further explored by the means of the efficiency effects model. Results of the analysis suggest that the lowest level and the highest variation of the technical efficiency were observed for the crop farms. Therefore, additional inefficiency factors underlying the crop farming need to be identified and tackled in order to improve the agricultural performance. The optimal farm size projections can also be made on a basis of the stochastic production functions. The future researches should also seek to increase the sample size by employing unbalanced panel data.

\section{References}

Alvarez, A.; Arias, C. 2004. Technical efficiency and farm size: a conditional analysis, Agricultural Economics 30: 241-250. http://dx.doi.org/10.1111/j.1574-0862.2004.tb00192.x

Baležentis, T.; Kriščiukaitienè, I. 2012. Family farm efficiency across farming types in Lithuania and its managerial implications - data envelopment analysis, Management Theory and Studies for Rural Business and Infrastructure Development 30(1): 22-30.

Bogetoft, P.; Otto, L. 2011. Benchmarking with DEA, SFA, and R. International Series in Operations Research and Management Science, Vol. 157. Springer.

http://dx.doi.org/10.1007/978-1-4419-7961-2

Bojnec, S.; Latruffe, L. 2011. Farm size and efficiency during transition: insights from Slovenian farms, Transformations in Business and Economics 10(3): 104-116.

Bravo-Ureta, B. E.; Solís, D.; López, V. H. M.; Maripani, J. F.; Thiam, A.; Rivas, T. 2007. Technical efficiency in farming: a meta-regression analysis, Journal of Productivity Analysis 27(1): 57-72. http://dx.doi.org/10.1007/s11123-006-0025-3 
Caves, D. W.; Christensen, L. R.; Diewert, W. E. 1982. The economic theory of index numbers and the measurement of input, output, and productivity, Econometrica 50(6): 1393-1414. http://dx.doi.org/10.2307/1913388

Chou, Y. C.; Shao, B. B. M.; Lin, W. T. 2012. Performance evaluation of production of IT capital goods across OECD countries: a stochastic frontier approach to Malmquist index, Decision Support Systems 54(1): 173-184. http://dx.doi.org/10.1016/j.dss.2012.05.003

Christensen, L. R.; Jorgenson, D. W.; Lau, L. J. 1971. Conjugate duality and the transcendental logarithmic production function, Econometrica 39: 255-256.

Christensen, L. R.; Jorgenson, D. W.; Lau, L. J. 1973. Transcendental logarithmic production frontiers, The Review of Economics and Statistics 55(1): 28-45. http://dx.doi.org/10.2307/1927992

Cobb, C.; Douglas, P. H. 1928. A theory of production, American Economic Review 18: 139-165.

Coelli, T. J.; Rao, D. S. P.; O’Donnell, C. J.; Battese, G. E. 2005. An introduction to efficiency and productivity analysis. Springer.

Davidova, S.; Latruffe, L. 2007. Relationships between technical efficiency and financial management for Czech Republic farms, Journal of Agricultural Economics 58(2): 269-288.

http://dx.doi.org/10.1111/j.1477-9552.2007.00109.x

Färe, R.; Grosskopf, S.; Lindgren, B.; Roos, P. 1992. Productivity changes in Swedish pharmacies 1980-1989: a non-parametric Malmquist approach, Journal of Productivity Analysis 3: 85-101. http://dx.doi.org/10.1007/BF00158770

Fuentes, H. J.; Grifell-Tatje, E.; Perelman, S. 2001. A parametric distance function approach for Malmquist productivity index estimation, Journal of Productivity Analysis 15(2): 79-94. http://dx.doi.org/10.1023/A:1007852020847

Gorton, M.; Davidova, S. 2004. Farm productivity and efficiency in the CEE applicant countries: a synthesis of results, Agricultural Economics 30: 1-16.

http://dx.doi.org/10.1111/j.1574-0862.2004.tb00172.x

Henningsen, A. 2009. Why is the Polish farm sector still so underdeveloped?, Post-Communist Economies 21(1): 47-64. http://dx.doi.org/10.1080/14631370802663646

Jack, L.; Boone, J. 2009. Sustainable change and benchmarking in the food supply chain, in L. Jack (Ed.). Benchmarking in food and farming. Gower.

Latruffe, L.; Balcombe, K.; Davidova, S.; Zawalinska, K. 2004. Determinants of technical efficiency of crop and livestock farms in Poland, Applied Economics 36(12): 1255-1263.

http://dx.doi.org/10.1080/0003684042000176793

Murillo-Zamorano, L. R. 2004. Economic efficiency and frontier techniques, Journal of Economic Surveys 18(1): 33-45. http://dx.doi.org/10.1111/j.1467-6419.2004.00215.x

Nauges, C.; O’Donnell, C. J.; Quiggin, J. 2011. Uncertainty and technical efficiency in Finnish agriculture: a state-contingent approach, European Review of Agricultural Economics 38(4): 449-467. http://dx.doi.org/10.1093/erae/jbr014

Petrick, M.; Kloss, M. 2012. Drivers of agricultural capital productivity in selected EU member states. Factor Markets, Working Paper 30. Centre for European Policy Studies, Brussels.

Rasmussen, S. 2011. Estimating the technical optimal scale of production in Danish agriculture, Food Economics - Acta Agriculturae Scandinavica, Section C 8(1): 1-19.

Samarajeewa, S.; Hailu, G.; Jeffrey, S. R.; Bredahl, M. 2012. Analysis of production efficiency of beef/calf farms in Alberta, Applied Economics 44: 313-322.

http://dx.doi.org/10.1080/00036846.2010.507173

Zhan, T. 2012. A Monte Carlo analysis for stochastic distance function frontier, Inzinerine Ekonomika - Engineering Economics 23(3): 250-255. 


\section{APPENDIX}

A least significant difference $t$ test for means of TE scores across different farming types.

Mean Square Error: 0.009139696

\begin{tabular}{lccccc}
\hline & Mean TE & SE & replication & LCL & UCL \\
\hline Crop & 0.7713 & 0.0034 & 890 & 0.765 & 0.778 \\
\hline Livestock & 0.7994 & 0.0059 & 137 & 0.788 & 0.811 \\
\hline Mixed & 0.7733 & 0.0059 & 173 & 0.762 & 0.785 \\
\hline
\end{tabular}

Alpha: 0.05 ; Df Error: 1197.

Critical value of $\mathrm{t}: 1.961948$.

Least significant difference 0.0182516 .

Harmonic mean of cell sizes 211.2198.

Means with the same letter are not significantly different

\begin{tabular}{cccc}
\hline Groups & & Treatments & Means \\
\hline $\mathrm{a}$ & Livestock & 0.79935 \\
\hline $\mathrm{b}$ & Mixed & 0.77329 \\
\hline $\mathrm{b}$ & Crop & 0.77134 \\
\hline
\end{tabular}

Comparison between treatments means

\begin{tabular}{lccccc}
\hline & Difference & p-value & sig & LCL & UCL \\
\hline Livestock - Crop & 0.0280 & 0.0014 & $* *$ & 0.0108 & 0.0452 \\
\hline Mixed - Crop & 0.0020 & 0.8060 & & -0.0136 & 0.0175 \\
\hline Livestock - Mixed & 0.0261 & 0.0173 & $*$ & 0.0046 & 0.0475 \\
\hline
\end{tabular}

Notes: Significance codes: $* *-0.01 ; *-0.05$.

Tomas BALEŽENTIS. He is a Senior Research Fellow at Lithuanian Institute of Agrarian Economics and holds $\mathrm{PhD}$ degrees from Vilnius University and University of Copenhagen. Dr Baležentis has published over 70 peer-reviewed papers on multi-criteria decision making, efficiency analysis, and agricultural economics in such outlets as Agricultural Economics, European Journal of Operational Research, Expert Systems with Applications, and Fuzzy Sets and Systems. 